DOE/ER/54212-5

LRC-97-67

\title{
Final Report for DOE Grant No. DE-FG03-93ER54212
}

\author{
Project Title: Fundamental Studies of Fusion Plasmas \\ Principle Investigator: James R. Myra \\ Period Covered by Report: $\quad$ 5/1/93 through 12/14/97 \\ Date of Report: $\quad$ December 15, 1997 \\ Recipient Organization: Lodestar Research Corporation \\ 2400 Central Ave., P-5 \\ Boulder, CO 80301 \\ DOE Award No.: $\quad$ DE-FG03-93ER54212 \\ Anticipated Amount of $\$ 0$ \\ Unexpended Funds at 12/14/97:
}

DISTRIBUTON OF THIS DOCUWENT IS UNLIMTED

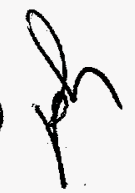




\section{DISCLAMER}

This report was prepared as an account of work sponsored by an agency of the United States Government. Neither the United States Government nor any agency thereof, nor any of their employees, makes any warranty, express or implied, or assumes any legal liability or responsibility for the accuracy, completeness, or usefulness of any information, apparatus, product, or process disclosed, or represents that its use would not infringe privately owned rights. Reference herein to any specific commercial product, process, or service by trade name, trademark, manufacturer, or otherwise does not necessarily constitute or imply its endorsement, recommendation, or favoring by the United States Government or any agency thereof. The views and opinions of authors expressed herein do not necessarily state or reflect those of the United States Government or any agency thereof. 


\section{DISCLAIMER}

Portions of this document may be illegible electronic image products. Images are produced from the best available original document. 


\section{Executive Summary}

In the course of this grant, Lodestar has collaborated with the TFTR ICRF team to carry out an extensive investigation of rf-edge physics relevant to the understanding and operation of the TFTR fast wave (FW) and ion Bernstein wave (IBW) antennas.

Our FW work covered four main areas: rf sheath geometry on TFTR, ICRF convective cells and edge profile modifications, impurity production, and plasma glow and Fermi acceleration. The differences between "new" and "old" Bay-M antennas with respect to sheath formation were understood, and a new approach to antenna analysis, the ANSAT code, was applied to the TFTR Bay-M antenna. Calculations were found to be in accord with experimental observations of "hot spots" on the corners and impurity observations. ICRF convective cells for TFTR were modeled and, in collaboration with ORNL, the modeling was compared with experimental (reflectometer) observations of edge density profile modifications. The rf-driven convective cell model originally developed for JET was extended to apply to the TFTR situation. The revised theory was able to model the reflectometer data. The impurity production rate at the antenna was calculated and compared with radiated power and spectroscopy data and satisfactory agreement was obtained. Finally, a plausible explanation of an observed Faraday screen (FS) glow phenomenon was given in terms of an if Fermi acceleration model.

Our IBW work, carried out over the last two years, was in support of the IBW transport barrier and poloidal flow generation experiments. A theoretical survey of rf-edge physics expected to be critical for these antennas was carried out. While the physics that was known to be important for FW systems was considered (especially sheath power dissipation, edge density modifications, and impurities), additional physics enters for IBW waves because of the shorter wavelength, slower group velocity, larger electric fields and the different polarization. In particular, ponderomotive forces, while normally negligible in the FW context, can be substantial for the IBW, but the jitter excursion distance of an electron is too large for validity of the usual theory. A new model for the resulting electron heating and density expulsion was developed. A new model of antenna coupling to the electron plasma wave, mode transformation to the IBW, and the effect of reflected waves at the lower hybrid layer was also developed. The latter are shown to be important when sharp density gradients are present, such as could be generated by nonlinear (ponderomotive-like) steepening. These nonlinear effects were found to exacerbate the generation of parasitic coaxial modes in the halo plasma. A recently completed theoretical study of these coaxial modes found several points of contact with experimental data. This work lends support to the role of ponderomotive forces and sheath power dissipation in causing unwanted power dissipation in the SOL plasma during IBW experiments. 


\section{RF Sheath Geometry on TFTR}

Our first task under this grant was to identify important features of the rf sheaths in TFTR geometry. RF sheath formation requires a field line connection between conductors (e.g. the Faraday screen and limiters) on which a substantial rf voltage is induced. Therefore, the magnitude and location of $\mathrm{rf}$ sheaths depend on the field line connections in the vicinity of the antenna. We have compared several types of connections for the "old" and "new" Bay M geometry on TFTR, including sheath voltages driven by both feeders and the central antenna conductor. In each case the sheath voltage and effective surface area was estimated. It is useful to distinguish between two types of sheaths on TFTR: screen-limiter sheaths (linking the FS to the rf limiter $1.7 \mathrm{~m}$ downstream along the field line) and screen-screen sheaths (linking the front faces of two "Vee shaped" FS elements). It was shown that an important and potentially dangerous class of screen-limiter sheaths was eliminated by extending the antenna bumper tiles with respect to the Faraday screen. 1

The newly developed ANSAT (ANtenna Sheath Analysis Tool) code 2,3 was applied to the Bay-M antenna to quantify the sheath voltages of screen-screen and screenlimiter sheaths. It was shown ${ }^{2}$ that the ANSAT analysis for the TFTR Bay-M antenna was quite different from a simple model ${ }^{4}$ previously used to describe JET. Relatively large sheath voltages occurred in the model for $0-\pi$ phasing, especially near the corners of the antenna. These calculations are in accord with experimental observations of "hot spots" on the corners and impurity observations (see below). The theory gives a qualitative, and sometimes quantitative, understanding of many of the features of the experiments reported in Refs. 5 and 6.

\section{ICRF Convective Cells and Edge Profile Modifications}

The rf sheaths cause rectification or self-biasing of the field lines on which they exist. Poloidal and radial variations in this dc voltage lead to $\mathrm{E} \times \mathrm{B}$ plasma convection, ${ }^{7}$ which works to modify the density profile and plasma flux to the screen. The density at and near the antenna is important both for antenna sheath interactions and antenna loading calculations. Convective cell modeling work originally done for $\mathrm{JET}^{7}$ was extended in this grant to include streamlines hitting the FS (i.e. $\mathrm{E} \times \mathrm{B}$ convection directly into the antenna). This phenomenon was seen in the ANSAT results ${ }^{2}$ and was found to be necessary to adequately model the reflectometer data. ${ }^{8}$ It was shown that the antenna density goes down in the presence of strong convection (high power), but the flux of plasma goes up, resulting in increased impurity production, local power dissipation, and other sheath effects. It may also play a role in the plasma glow observed on the old Bay $M$. 
For typical TFTR parameters, we have calculated that the effective perpendicular transport driven by the screen-screen and screen-limiter sheaths is large compared to Bohm in both $0-0$ and $0-\pi$ phasings, so that the flux at the screen is enhanced compared to the value predicted for Bohm diffusion. In $0-\pi$ phasing, the convective cells are due to the screen-limiter sheaths. The enhanced perpendicular transport coefficient is used in the impurity calculations described below.

\section{Impurity Production}

Employing our rf sheath impurity influx model, ${ }^{4}$ modified to take into account TFTR geometry, we have estimated the sheath driven impurity influxes including sputtering of both $\mathrm{D}$ and $\mathrm{C}$ on $\mathrm{Ti}$ and summing the contributions of both screen-screen and screen-limiter sheaths. The main results of this work are the following. It was found that many of the experimentally observed ICRF-edge plasma interactions on TFTR in the period 1988 - 1994 are consistent with the predictions of if sheath theory, given reasonable assumptions about unknown edge parameters. For example, the theory is consistent with the data on the antenna glow and the titanium influx from the TiC-coated Faraday screens (FS). The available data was consistent with calculations of $\delta \mathrm{Z}_{\mathrm{eff}}$ (Ti) assuming the only source of titanium was the FS. ${ }^{9}$ The importance of ionization screening was demonstrated from the TFTR data and the modeling. ${ }^{10}$ We have also tested a new approach 2,3 to rf sheath and impurity analysis during this contract. In the new approach, our previous analytic rf sheath voltage models are replaced by numerical calculations of the 3D sheath voltage distribution on the antenna using the ANSAT code, which uses the rf field distribution calculated by a 3D antenna code such as ARGUS.

The new analysis gives much more accurate and detailed information about the rf sheath voltage distribution, including all sources (straps and feeders, inductive and capacitive effects) and can be used to identify undesirable high-sheath-voltage points in the antenna design. The location of the highest voltage sheaths in this analysis agrees with the observed locations of the antenna glow (the "hot spots"). Another interesting result for antenna designers is that the ANSAT analysis of TFTR and a comparison of the experimental data strongly suggest that rf sheath formation on the TFTR antennas is quite different than on the JET A1 antennas. The high-voltage sheaths in some corners of the TFTR antennas (probably due to the slotted side walls) did not seem to be as prominent for the JET A1 antenna design without slotted sidewalls. These sheaths cause the observed antenna glow and do not disappear in $\pi$ phasing; correspondingly, the TFTR data ${ }^{11}$ shows less of a phasing dependence than the JET data previously analyzed. ${ }^{12-14} \mathrm{~A}$ careful comparison of our ANSAT-based impurity influx calculations and the experimentally- 
determined Ti influxes for a series of experiments on mode conversion current drive (MCCD) in March, 1994, which compared electron heating in $\pi$ phasing with co- and counter-MCCD in $\pi / 2$ phasing, has been carried out. 15,16

\section{Plasma Glow and Fermi Acceleration}

The phenomenon of plasma glow along field lines connecting to the antenna, which was especially prominent in the "old" Bay-M geometry, was studied. ${ }^{17}$ A plausible explanation of the glow phenomenon was given in terms of an if Fermi acceleration model, which describes the heating of edge electrons by glancing angle interactions with if sheaths. The calculated spatial dependence of the screen-limiter sheath voltage predicts a maximum sheath potential at the spatial location where the glow was observed, and the mechanism of Fermi acceleration ${ }^{18,19}$ of electrons by the sheaths provides a means for increased ionization and excitation of atoms in the SOL. For the screen-limiter sheaths, the B-field line intersects the FS face at a near glancing angle $\psi$ so that the sheath can cause electron edge heating by an analog of the usual Landau damping mechanism. Calculations reported in Ref. 17 describe the electron rf-sheath interaction in the small $\psi$ regime. The net electron heating depends on the competition of Fermi acceleration with electron losses including perpendicular transport (e.g. If convection) and parallel losses through the sheath.

\section{IBW Edge Physics: Introduction}

Experiments on PBX-M have shown that the IBW offers exciting possibilities for advanced tokamak physics by driving enhanced performance modes in the core of tokamak plasmas. ${ }^{20}$ Intense IBW interactions with the core plasma occur through the Reynold's stress, ${ }^{21}$ which can be regarded as part of the generalized ponderomotive force. Recent experiments on TFTR 22 have demonstrated the presence of an IBW-induced velocity shear layer, presumably due to these nonlinear interactions. Nonlinear physics is perhaps even more important in describing the interaction of the IBW with the edge plasma. The edge interaction plays an important role in determining the details of the wave coupling, the antenna loading and parasitic heating, the SOL density profile, and the generation of rfspecific impurities.

Past experiments ${ }^{23}$ have shown the rich physics of IBW launch and the importance of nonlinear effects in the rf-edge plasma. Large ponderomotive potentials exist because of the large $E_{\|}$in the IBW polarization, and these are expected to lead to expulsion of plasma near the antenna. Anomalous loading was observed on previous DIII-D ${ }^{24}$ and Alcator- $\mathrm{C}^{25}$ IBW heating experiments. Impurity influx has also been a concern in some situations. As 
described above, we have previously been collaborating with the TFTR ICRF group in studying the edge interactions induced by fast wave (FW) antennas. Many of the same issues exist, and can be enhanced in some regimes, with the IBW polarization. These include impurity generation by rf-enhanced sputtering 4 (projectile ions are accelerated to high energy in the if sheaths), modifications of the density profile in front of the antenna by rf-induced convective cells ${ }^{7}$ and ponderomotive expulsion, 24 and rf-sheath effects on antenna loading. 26,27

In the first year of the IBW studies, Lodestar completed a survey of the most important linear and nonlinear physics affecting antenna loading and the ability to couple IBW power to the plasma. ${ }^{28}$ We have identified regimes in the operational parameter space of power (antenna voltage), frequency and density (at the antenna) in which ponderomotive-like expulsion, nonlinear electron edge heating, parasitic sheath-plasmawave generation, ${ }^{26}$ and sheath power dissipation ${ }^{27}$ act. The survey suggested that important information could be learned by examining the power dependence of the loading. Such experiments were ultimately conducted on TFTR and have provided important information for interpreting the experiments (see below) by comparing loading studies at very low power $(\mathrm{P} \sim 1 \mathrm{~kW})$ with those at the $\mathrm{MW}$ level.

\section{Nonlinear Density Expulsion in IBW Experiments}

For operation at high power and low density at the antenna, ponderomotive-like physics is important. We have developed a ponderomotive density expulsion and electron heating model, ${ }^{29}$ valid in the high power TFTR IBW regime, when the usual ponderomotive theory does not apply because of large parallel electron if excursions. The model is characterized by the parameters $\alpha=m_{e} \omega v_{\|} / e E_{\|}, \beta_{L}=m_{e} \omega^{2} L_{\|} / e E_{\|}$, and $\beta_{1}=$ $m_{e} \omega^{2} l_{\|} / e E_{\|,}$, where $v_{\| /}$is the initial parallel velocity of an electron along a field line which passes in front of the antenna, $\omega$ is the rf wave frequency, $E_{\|}$is the rf field strength, $1_{\|}$is a characteristic parallel scale length over which $E_{\|}$changes, and $L_{\|}$is the length of the antenna. The parameter $\alpha$ is the ratio of $v_{1 !}$ to the electron "quiver" velocity; $\beta_{L}$ and $\beta_{1}$ are the ratios of $L_{\| \mid}$and $l_{\| \mid}$to the quiver excursion distance, respectively. Since $v_{\|}$is of the order of the electron thermal velocity, $\alpha$ is related to the ponderomotive potential $\psi$ by $\mathrm{e} \psi / \mathrm{T}_{\mathrm{e}} \sim 1 / \alpha^{2}$. Frequently, ponderomotive theory is done in the limit $\alpha \gg 1$, though arbitrary $\alpha$ is possible in some cases; 30 however, then $\beta_{1} \gg 1$ has previously been assumed. Different, but related extensions of ponderomótive theory to include nonadiabatic (transit-time) effects have previously been considered in the literature, ${ }^{31-32}$ but are not directly applicable here because they employ perturbation in the electric field amplitude, i.e. $\alpha \gg$ 1. Finite amplitude effects and non-adiabaticity have been considered by Kono et 
al., 33 but for a model geometry that is not relevant here. The model developed here employs arbitrary $\alpha$ and $\beta_{L}$, with $\beta_{1} \ll 1$, and therefore is complementary to the usually studied case. We find that ponderomotive-like density expulsion still occurs in the small $\alpha$ (strong if field) limit, but with an algebraic $(\sim \alpha)$ rather than exponential $\left[\exp \left(-\psi / T_{e}\right)\right]$ dependence on wave amplitude. The expulsion of density in front of the antenna is beneficial in that it mitigates if sheath interactions and impurity generation, but concomitant steepening of the density profile may lead to imperfect linear mode transformation of the launched electron plasma wave (EPW) to the IBW at the LH layer, i.e. to reflected power which degrades coupling to the core plasma.

In addition to density expulsion, the model directly gives the strong electron heating that occurs when $\alpha \lesssim 1$. This effect has also been discussed by Carter in a slightly different context. ${ }^{34}$ A typical electron is accelerated from its initial thermal velocity, to a velocity of the order of the "jitter" velocity in the rf, viz. $\mathrm{eE}_{\|} / \mathrm{m}_{\mathrm{e}} \omega$, with the exact velocity gain being dependent on the relative phase of the electron motion and the wave. A phase averaging technique is normally employed to calculate quantities of interest. Numerical estimates for the TFTR case show that the net power lost to electron heating by this process is too small to be a concern, but because the electron heating is localized to a small volume in the SOL, deleterious local power deposition on the antenna bumper and limiter surfaces may be an issue.

\section{Mode Transformation Physics and Induced Reflection in IBW experiments}

In order to assess the possible effects of nonlinear density profile modification, and also to improve our understanding of the linear physics of mode transformation, another model has been developed which enables us to calculate the antenna loading and reflected power for an arbitrary density profile. We recall that linear theory ${ }^{23}$ describes two regimes for launching the IBW. In one regime, the density at the antenna is above the value at which $\omega=\omega_{\mathrm{lh}}$, where $\omega_{\mathrm{lh}}$ is the LH frequency, so that the IBW is propagating and can be launched directly, hence this is called the "direct launch" regime. In the direct launch regime, our estimates indicate that if sheaths are likely to be an issue because of the large voltages that the antenna excites along a field line and the high density at the antenna surface. Furthermore, both theoretical ${ }^{26}$ and experimental ${ }^{24}$ work suggests a large anomalous loading occurs in this case. For these reasons, the "indirect launch" regime is of great interest. In this scheme, the density at the antenna is below the LH critical density, so that the propagating mode that is launched is the electron plasma wave (EPW). In this case, the antenna coupling problem has been treated by Chiu et al. ${ }^{35}$ using a cold plasma 
model. Linear WKB theory ${ }^{23}$ would then describe perfect (reflectionless) mode transformation of the EPW to the IBW near the LH layer.

When the conditions for validity of the WKB approximation are not met, i.e. when the density gradient at the LH layer is steep, analytical estimates confirm that significant reflection can occur. To describe this situation, a new second order wave equation containing the IBW and EPW has been developed. The procedure is similar to one proposed by Brambilla et al., 36 but the present equation remains valid across the LH layer. Our equation also circumvents the problems associated with spurious roots that often plague higher order equations obtained by direct expansion of the Bessel function dispersion relations in $k_{\perp} \rho .{ }^{37} \mathrm{~A}$ numerical code, which inputs the density profile and $\mathrm{k}_{\|}$of the EPW at the antenna has been developed to calculate the reflected power, and the net loading into the IBW after imperfect mode transformation. ${ }^{38}$ It was shown that almost total reflection occurs when the density gradient is steep (causing violation of the WKB conditions) near the LH layer. Reflections could be somewhat reduced by launching the EPW into a higher density plasma (i.e. moving the antenna front surface closer to the LH layer).

The importance of the density profile to mode transformation, and the strong role of ponderomotive density expulsion, motivated the development of a model which treated both the EPW/IBW wave fields and the nonlinear density profile evolution selfconsistently. ${ }^{39}$ This work (performed under a separate grant) showed that a large fraction of the launched power can be reflected back towards the antenna and halo plasma for parameters corresponding to high power operation on TFTR.

\section{Role of the Coaxial Mode in IBW experiments on TFTR}

When the launched EPW is reflected at LH layer, it is expected that a standing EPW wave could be trapped in the halo plasma between the LH layer and the vacuum vessel wall. In a recently completed study 40 we have shown that this mode, hereafter referred to as the "coaxial mode" (CM), has important implications for understanding IBW experiments on TFTR.

In recent IBW heating experiments on TFTR ${ }^{22}$ a velocity shear layer in the plasma core was obtained. The magnitude of velocity shear was believed to be too small to create an internal transport barrier because of parasitic edge processes which reduced the power coupled to the core. Models were developed to further understand these observations by examining the role of coaxial modes and their dissipation in edge processes including rf plasma sheaths. 
Our work resulted in an understanding of three experimental observations on TFTR: (i) $\mathrm{P}_{\text {core }} / \mathrm{P}_{\mathrm{rf}} \ll 1$, (ii) $\mathrm{R}_{\mathrm{L}}$ depends on poloidal phasing with loading higher in 0-00-0 phasing, and (iii) $R_{L}$ depends on $P_{r f}$, hence some nonlinear processes are at work. Here $P_{\text {core }}$ is the power coupled to the core, $P_{\mathrm{rf}}$ is the total $\mathrm{rf}$ power launched, and $\mathrm{R}_{\mathrm{L}}$ is the antenna loading resistance. Point (i) follows from either a large induced reflection and direct dissipation of the coaxial mode, ${ }^{40}$ or rf-sheath dissipation of the IBW while it is still in the SOL. 38 Data did not permit a discrimination of these two effects. Point (ii) was shown to follow from the propagation characteristics of the coaxial mode, ${ }^{40}$ and (iii) was shown to result from $\mathrm{rf}$-sheath dissipation of the coaxial mode in the halo plasma. ${ }^{40}$

From these studies, we were able to arrive at some general conclusions. While the utility of an IBW in the core plasma for heating, current drive, and other more exotic uses such as $\alpha$-channeling, provides strong motivation for continued work in IBW launch, the difficulty of coupling to such a short wavelength mode from relatively large hardware, such as a classical IBW antenna, is apparent. The strong nonlinearities inherent in coupling to an electrostatic mode with slow group velocity exasperates the situation. Perhaps fastwave to IBW mode conversion schemes which avoid the IBW launch issue entirely may provide a practical solution to these difficulties. Alternatively, phaseable waveguide launchers (to reduce $\mathrm{CM}$ coupling) operating at high frequency (to mitigate ponderomotive effects) may merit investigation. 


\section{Publications, Abstracts and Presentations}

R. Majeski, D.A. D'Ippolito, J.R. Myra, et al. in Proceedings of the 20th European Physical Society Conference on Controlled Fusion and Plasma Physics, Lisbon, (European Physical Society, 1993), Vol. 17C, Part III, p. 977.

J.R. Myra, D.A. D'Ippolito, R. Majeski and J.R. Wilson, J.H. Rogers, G. Schilling, J. Stevens, S. Raman, J.B. Wilgen, G.R. Hanson, Y.L. Ho, Bull. Am. Phys. Soc. 38, 2034 (1993), paper 6S27.

D.A. D'Ippolito, J.R. Myra, R. Majeski and J.R. Wilson, Bull. Am. Phys. Soc. 38, 2034 (1993), paper 6S28.

J.R. Myra, D.A. D'Ippolito, R. Majeski and J.R. Wilson, J.H. Rogers, J. Stevens, G.R. Hanson, J.B. Wilgen, A.E. England, Y.L. Ho, presented at the Seventh International RF Workshop on Current Drive and Profile Control for Advanced Tokamaks, April 6-8, 1994, Boulder CO.

D.A. D'Ippolito, J.R. Myra, R. Majeski and J.R. Wilson, Bull. Am. Phys. Soc., Plasma Phys. 39, 1627 (1994), paper 4R17.

J.R. Myra, D.A. D'Ippolito, and R. Majeski, in Proceedings of the 21st European Physical Society Conference on Controlled Fusion and Plasma Physics, Montpellier, (European Physical Society, 1994), Vol. 18B, Part II, p. 894.

J.R. Myra and D.A. D'Ippolito, Bull. Am. Phys. Soc., Plasma Phys. 41, 1428 (1996), paper $3 P 19$.

J.R. Myra and D.A. D'Ippolito, Phys. of Plasmas 4, 3187 (1997).

J.R. Myra, D.A. D'Ippolito, D.A. Russell, and J.H. Rogers, in AIP Conference Proceedings 403: Eleventh Topical Conference on Radio-Frequency Power in Plasmas, (AIP, New York, 1997), p. 459.

D.A. Russell, J.R. Myra and D.A. D'Ippolito, in AIP Conference Proceedings 403: Eleventh Topical Conference on Radio-Frequency Power in Plasmas, (AIP, New York, 1997), p. 455.

J.C. Hosea, R. Bell, K. Hill, B. LeBlanc, R. Majeski, R. Nazikian, M. Ono, C.K. Phillips, J.H. Rogers, G. Schilling, J.R. Wilson, D.A. D'Ippolito, J.R. Myra, C.E. Bush and G.R. Hanson, in AIP Conference Proceedings 403: Eleventh Topical Conference on Radio-Frequency Power in Plasmas, (AIP, New York, 1997), p. 77.

D.A. D'Ippolito, J.R. Myra, J.H. Rogers, K.W. Hill, J.C. Hosea, R. Majeski, G. Schilling, J.R. Wilson, G.R. Hanson, A.C. England and J.B. Wilgen, in Proceedings of the Twenty-Fourth EPS Conference on Controlled Fusion and Plasma Physics, Berchtesgaden, Germany, 1997, Vol. 21A, Part III, p. 1077.

D.A. D'Ippolito, J.R. Myra, J.H. Rogers, K.W. Hill, J.C. Hosea, R. Majeski, G. Schilling, J.R. Wilson, G.R. Hanson, A.C. England and J.B. Wilgen, Lodestar Research Corporation Report \#LRC-97-63 (1997), to be submitted to Phys. of Plasmas.

J.R. Myra, D.A. D'Ippolito, D.A. Russell, J.H. Rogers, J.C. Hosea, J.R. Wilson, T. Intrator, Bull. Am. Phys. Soc., Plasma Phys. 42, 2042 (1997), paper pThpP2-26.

J.R. Myra, D.A. D'Ippolito, D.A. Russell, J.H. Rogers, J.C. Hosea, J.R. Wilson, T. Intrator, (1997), Report in Preparation. 


\section{References}

1. R. Majeski, et al. in Proceedings of the 20th European Physical Society Conference on Controlled Fusion and Plasma Physics, Lisbon, (European Physical Society, 1993), Vol. 17C, Part III, p. 977.

2. J.R. Myra, D.A. D'Ippolito and Y.L. Ho, Fusion Eng. Des. 31, 291 (1996).

3. J.R. Myra, D.A. D'Ippolito and Y.L. Ho, in Proceedings of the Eleventh Topical Conference on Radio Frequency Power in Plasmas , (AIP, New York, 1996), p. 405.

4. D.A. D'Ippolito, J.R. Myra, M. Bures, and J. Jacquinot, Plasma Phys. Cont. Fusion 33, 607 (1991).

5. J. Stevens et al., in Proceedings of the Eighth Topical Conference on Radio Frequency Power in Plasmas, Irvine, CA, (AIP, New York, 1989), p. 342.

6. J. Stevens et al., Plasma Phys. Contr. Fus. 32, 189, 1990.

7. D.A. D'Ippolito, J.R. Myra, J. Jacquinot, and M. Bures, Phys. Fluids B 5, 3603 (1993).

8. D.A. D'Ippolito, J.R. Myra, A.C. England, G.R. Hanson, J.B. Wilgen, J.H. Rogers, R. Majeski, G. Schilling, J.R. Wilson and J.C. Hosea, in Proceedings of the Eleventh Topical Conference on Radio Frequency Power in Plasmas, (AIP, New York, 1996), p. 467.

9. D.A. D'Ippolito, J.R. Myra, R. Majeski and J.R. Wilson, Bull. Am. Phys. Soc. 38, 2034 (1993), paper 6S28.

10. J.R. Myra, D.A. D'Ippolito, R. Majeski and J.R. Wilson, J.H. Rogers, G. Schilling, J. Stevens, S. Raman, J.B. Wilgen, G.R. Hanson, Y.L. Ho, Bull. Am. Phys. Soc. Plasma Phys. 38, 2034 (1993), paper 6S27.

11. D.A. D'Ippolito, J.R. Myra, R. Majeski and J.R. Wilson, Bull. Am. Phys. Soc. 39, 1627 (1994), paper 4R17.

12. D.A. D'Ippolito, J.R. Myra, M. Bures, and J. Jacquinot, Plasma Phys. Cont. Fusion 33, 607 (1991).

13. M. Bures, J. Jacquinot, K. Lawson, M. Stamp, H.P. Summers, D.A. D'Ippolito, J.R. Myra, Plasma Phys. Cont. Fusion 33, 937 (1991).

14. M. Bures, J. Jacquinot, M. Stamp, D. Summers, D. Start, T. Wade, D. D'Ippolito, and J. Myra, Nucl. Fusion 32, 1139 (1992).

15. D.A. D'Ippolito, J.R. Myra, J.H. Rogers, K.W. Hill, J.C. Hosea, R. Majeski, G. Schilling, J.R. Wilson, G.R. Hanson, A.C. England and J.B. Wilgen, in Proceedings of the Twenty-Fourth EPS Conference on Controlled Fusion and Plasma Physics, Berchtesgaden, Germany, 1997, Vol. 21A, Part III, p. 1077.

16. D.A. D'Ippolito, J.R. Myra, J.H. Rogers, K.W. Hill, J.C. Hosea, R. Majeski, G. Schilling, J.R. Wilson, G.R. Hanson, A.C. England and J.B. Wilgen, Lodestar Research Corporation Report \#LRC-97-63 (1997).

17. J.R. Myra, D.A. D'Ippolito, and R. Majeski, in Proceedings of the 21st European Physical Society Conference on Controlled Fusion and Plasma Physics, Montpellier, (European Physical Society, 1994), Vol. 18B, Part II, p. 894.

18. M.A. Lieberman, IEEE Trans. Plasma Sci. PS-16, 638 (1988); C.G. Goedde et al., Univ. California Berkely Report UCB/ERL M88/29 (1988)

19. M.D. Carter, D.B. Batchelor and E.F. Jaeger, Phys. Fluids 4, 1081 (1992).

20. B. LeBlanc, M. Ono, W. Tighe, J. Dunlap et al., in AIP Conference Proceedings 289 - Radio Frequency Power in Plasmas, Boston, MA (AIP, New York, 1994), p. 68.

21. H. Biglari, M. Ono, P.H. Diamond and G.C. Craddock, in AIP Conference Proceedings 244 - Radio Frequency Power in Plasmas, Charleston SC, USA (AIP, New York, 1992), p. 376. 
22. J.H. Rogers, R.E. Bell, S. Bernabei, J.C. Hosea, B. LeBlanc, R. Majeski, R. Nazikian, M. Ono, C.K. Phillips, G. Schilling, J.R. Wilson, C.E. Bush, D.A. D'Ippolito, G.R. Hanson and J.R. Myra, in AIP Conference Proceedings 403 -

Radio Frequency Power in Plasmas, Savannah, GA (American Institute of Physics, New York, 1997), p. 13.

23. M. Ono, Phys. Fluids B 5, 241 (1993).

24. M.J. Mayberry, R.I. Pinsker, C.C. Petty, M. Porkolab, S.C. Chiu, W.P. Cary, R. Prater, Nucl. Fusion 33, 627 (1993).

25. J.D. Moody et al., Phys. Fluids B1, 1675 (1989).

26. J.R. Myra, D.A. D'Ippolito, D.W. Forslund and J.U. Brackbill, Phys. Rev. Lett. 66, 1173 (1991).

27. D.A. D'Ippolito and J.R. Myra, Phys. of Plasmas 3, 420 (1996).

28. J.R. Myra and D.A. D'Ippolito, Bull. Am. Phys. Soc., Plasma Phys., 41, 1428 (1996), paper 3P19.

29. J.R. Myra and D.A. D'Ippolito, Phys. of Plasmas 4, 3187 (1997).

30. see for example J.R. Myra and P.J. Catto, Phys. Fluids B 1, 1193 (1989).

31. J.R. Myra and D.A. D'Ippolito, Phys. Rev. Lett. 53, 914 (1984); D.A. D'Ippolito and J.R. Myra, Phys. Fluids 28, 1895 (1985).

32. G. Dimonte, B.M. Lamb and G.J. Morales, Phys. Rev. Lett. 48, 1352 (1982).

33. M. Kono and R. Iwano, Phys. Fluids 31, 1297 (1988).

34. M. Carter, presented at the Ist Boulder Workshop on ICRF Edge Physics, March 30 - April 1, 1988, Boulder CO.

35. S.C. Chiu, M.J. Mayberry, R.I. Pinsker, C.C. Petty and M. Porkolab, in AIP Conference Proceedings 244 - Radio Frequency Power in Plasmas, Charleston SC, USA (AIP, New York, 1992), p. 169.

36. M. Brambilla and A. Cardinali, Nucl. Fusion 32, 465 (1992).

37. see for example C.Y. Wang, D.B. Batchelor and E.F. Jaeger, Phys. Plasmas 2, 2863 (1995); and refs. therein.

38. J.R. Myra, D.A. D'Ippolito, D.A. Russell, and J.H. Rogers, in AIP Conference Proceedings 403: Eleventh Topical Conference on Radio-Frequency Power in Plasmas, (AIP, New York, 1997), p. 459.

39. D.A. Russell, J.R. Myra and D.A. D'Ippolito, in AIP Conference Proceedings 403: Eleventh Topical Conference on Radio-Frequency Power in Plasmas, (AIP, New York, 1997), p. 455.

40. J.R. Myra, D.A. D'Ippolito, D.A. Russell, J.H. Rogers, J.C. Hosea, J.R. Wilson, T. Intrator, Bull. Am. Phys. Soc., Plasma Phys., 42, 2042 (1997), paper pThpP2-26; J.R. Myra, D.A. D'Ippolito, D.A. Russell, J.H. Rogers, J.C. Hosea, J.R. Wilson, T. Intrator, Report in Preparation. 